\title{
Application on Simulation Technology for Teaching the Course of Introduction to Computer Science
}

\author{
Jiangfeng Li, Chenxi Zhang \\ School of Software Engineering, Tongji University, Shanghai, China \\ Email address: \\ lijf@tongji.edu.cn (Jiangfeng Li), xzhang2000@163.com (Chenxi Zhang)

\section{To cite this article:} \\ Jiangfeng Li, Chenxi Zhang. Application on Simulation Technology for Teaching the Course of Introduction to Computer Science. Science \\ Discovery. Vol. 6, No. 5, 2018, pp. 429-435. doi: 10.11648/j.sd.20180605.28
}

Received: October 3, 2018; Accepted: November 7, 2018; Published: November 8, 2018

\begin{abstract}
The course Introduction to Computer Science is a basic course for undergraduate students majoring in computer science. It is the first time for the students to learn knowledge of computer science in college. There are a lot of problems in students' learning, such as boring learning and lack of interests. In this paper, related works of teaching methods using simulation technology are introduced firstly. Also, approaches of teaching for the course Introduction to Computer Science are presented. Then, features are analyzed for the course Introduction to Computer Science, and difficulties that students have been facing in learning the course are discussed. Next, simulation technology is used in teaching the course. Using the technology, softwares of simulators and related simulations for the course are designed and implemented. There are three simulators and six simulations that are used in teaching the course. The simulators include sorting algorithm simulator, binary operation simulator, and process management simulator. The first simulator is used for showing processes of sorting algorithms. The second one is used to run binary operations. The last one is used to display statuses of processes and operations of allocation in running multi-process tasks. Those simulators and simulations have good performances in teaching the course Introduction to Computer Science.
\end{abstract}

Keywords: Simulation Technology, Introduction to Computer Science, Software of Simulator, Course Teaching

\section{模拟仿真技术在计算机课程教学上的应用研究}

\author{
李汇峰, 张晨曦 \\ 软件学院, 同济大学, 上海, 中国 \\ 邮箱 \\ lijf@tongji.edu.cn（李江峰）, xzhang2000@163.com（张晨曦）
}

\begin{abstract}
摘要: 计算机基础是计算机本科的一门专业基础课程, 是学生在大学期间第一次学习计算机的基础知识, 存在着学习 枯燥、兴趣不高等问题。本文首先介绍了将模拟仿真技术应用在教学中的已有研究工作, 以及计算机基础课程的教学 方法研究现状。然后, 分析了计算机基础课程的特点和学生学习这门课程存在的难点。接着, 将模拟仿真技术运用到 计算机基础课程的教学中, 设计并实现了用于计算机基础课程教学的排序算法模拟器软件、二进制运算模拟器软件、 进程管理模拟器软件共 3 个仿真模拟器软件及其相关的模拟仿真实验。排序算法模拟器软件用于演示排序算法的排序过 程。二进制运算模拟器软件用于展现二进制运算的运行结果。进程管理模拟器软件用于模拟进程状态和多进程任务运 行时的进程调度。这些模拟器软件和仿真实验在计算机基础课程的教学中收到了很好的教学效果。
\end{abstract}

关键词: 模拟仿真技术, 计算机基础, 模拟器软件, 课堂教学 


\section{1. 引言}

计算机模拟仿真技术是一项常用技术，被广泛应用 于各行各业中。在课堂教学方面, 相关教学研究人员积 极运用模拟仿真技术, 取得了不少研究成果。王俊洁[1] 面向高校实训的教学环境, 提出了3D模拟仿真平台构建 方法。周凤玲[2]等人将计算机模拟仿真技术运用到电子 维修教学中, 效果很好。何伟[3]针对“互联网+”背景下 的计算机技术发展, 用计算机模拟仿真技术对高职《电 子商务》课程进行了实践教学改革。任国成 [4]等人以山 东建筑大学为例, 研究了数值模拟在材料成形原理中的 教学应用.

林威[5]提出了模拟仿真教学法, 并将该教学法应用 于英语专业实训课程中, 取得了不错的成果。陈智 [6] 等人在物流管理领域, 研究基于模拟仿真技术的实践教 学方法。这些研究人员在不同的课程教学研究中, 运用 计算机模拟仿真技术, 在各自的研究领域收获不少。由 此可见, 计算机仿真技术为课堂教学提供了强有力的技 术支撑。

计算机基础是一门非常重要的基础课程。在计算机基 础的教学中, 多种教学方法用于提升课程的教学效果。彭 振宇[7]提出了网络环境下计算机基础课程分类分层次的 教学方法。刘锋 [8]等人研究了“互联网+”教学模式的计算 机基础课程方法。万振环 [9]以岗位胜任力为导向, 研究了 大学计算机基础课程的教学方法。郘丽[10]提出了计算思 维的概念, 分析了计算思维在计算机科学导论课程改革中 的作用。邹羚[11]探索了大学计算机基础教学改革中存在 的问题, 并提出了教学改革方法。王茹娟[12]对高等教育 中的计算思维问题进行了研究分析。

以上研究成果对计算机基础课程的教学研究有重要 的借鉴意义。然而, 这些成果不能完全解决计算机基础课 程在课堂教学中出现的问题。

由于计算机基础课程是学生第一次学习计算机的基 础知识, 学生在学习这门课程之前, 对计算机还没有一个 系统的了解。加之有相当一部分的课程内容比较抽象、难 懂, 学生学起来更是感觉枯燥, 兴趣不高。现有计算机基 础的教学方法, 在提升学生学习效率、降低课程学习难度、 吸引学生兴趣方面, 效果并不太好。

为了解决这一问题, 将模拟仿真技术用在计算机基础 的课程教学上, 通过设计和实现仿真模拟器和相关的模拟 仿真实验, 有效地提高该课程的教学质量, 使之更加生动 形象。

仿真模拟器和模拟仿真实验的建设, 对学生学习计算 机基础课程有着重要的意义。首先, 利用运行在仿真模拟 器上的模拟仿真实验, 可以把抽象的内容形象地展现出来, 供学生仔细跟踪和分析。其次, 通过模拟仿真实验, 学生 能更清楚的了解计算机软硬件的基本工作原理。第三, 运 行模拟仿真实验, 并在实验信息平台上进行交流, 能有效 培养学生的学习兴趣, 激发学生的学习动力, 为学生今后 学习其他专业课程打下良好基础。

\section{2. 课程特点及难点}

\section{1. 课程内容的基础性}

计算机基础是一门大一新生的专业课程。该课程的教 学内容不仅涵盖面广, 基础性也很强。

在课程的涵盖面方面, 课程涉及计算机存储方法、计 算机系统结构、操作系统、计算机网络、算法、程序语言、 软件工程、数据结构、数据库、计算机图形学等多个方面 的内容。基本涵盖了计算机专业本科生培养计划中的主要 课程方向。

在课程的基础性方面, 计算机基础课程的授课目的, 就是为了给学生在后续课程的学习中打下基础。因此, 在 本科生培养计划中, 计算机基础课程是计算机组成原理、 计算机系统结构、操作系统、计算机网络、面向对象程序 设计、算法理论等十多门课程的先修课程。

由此可见, 计算机基础课程在整个计算机专业的学生 培养中，其基础地位不可动摇。

\section{2. 入门学习的复杂性}

计算机基础课程是面向大一新生的课程, 入学之初, 不少学生面对该课程, 容易产生陌生、困惑的不适情绪。 主要表现在:

第一, 思维方式的转换不适。绝大部分学生在从人脑 思维方式转换为电脑思维方式上, 存在难度。比如, 从传 统的十进制操作转换成二进制操作, 学生们就需要一个长 时间的习惯过程, 更不用说比二进制复杂很多的其他课程 内容了。

第二，应用场景的认知不适。在信息技术讯猛普及的 今天, 使用电脑、手机及其应用软件已经成为常态。以往 未曾全面、系统地学习过课程中的内容, 因此, 很多学生 对计算机原理和技术会有一些理解上的误区, 以为使用过 电脑、手机等工具, 就是了解硬件原理; 以为用过办工软 件、即时通讯软件, 就是掌握软件开发技术; 以为看过网 页、发过电子邮件就是明白计算机网络。而开始学习了计 算机基础课程后, 过去的认知被颠覆, 带来极大地陌生和 困惑感。

\section{3. 兴趣培养的必要性}

兴趣是学生不断学习的最主要动力, 培养学生的学习 兴趣, 能让学生在掌握书本内容、了解课外知识方面更有 学习主动性。

然而, 在计算机基础课程的学习中, 存在一些让学生 兴趣感不强的教学内容。比如, 在计算机存储、数据结构 等章节, 存在大量枯燥的概念; 在操作系统、计算机网络 等章节, 存在很多较为复杂的操作流程。学生在学习过程 中就产生了难度, 知识要点的理解不适, 这个时候, 兴趣 培养就无从谈起了。而学生一旦失去学习的兴趣, 这门课 程肯定无法学好。不仅影响计算机基础课程这一门课的学 习, 更影响计算机专业很多后续课程的学习。因此, 培养 计算机基础课程的学生学习兴趣很有必要。 


\section{3. 课程仿真模拟器软件的设计与实现}

为了使学生了解并掌握计算机算法、计算机系统结构、 操作系统等方面的主要基础知识, 设计并实现了仿真模拟 器及其模拟仿真实验。这些实验将有效地提高教学效果, 提高学生的学习兴趣。

这些仿真模拟器软件包括排序算法模拟器软件、二进 制运算模拟器软件、进程管理模拟器软件共 3 个仿真模拟 器软件。这些仿真模拟器软件在Windows操作系统上运行, 并提供很好的交互界面。

\section{1. 排序算法模拟器软件}

\subsection{1. 模拟仿真实验需求}

在排序算法模拟器软件上, 主要运行冒泡排序算法和 快速排序算法两个模拟仿真实验。

模拟器软件的主要需求是: 学生输入需要排序的一组 数字，选择冒泡排序算法或快速排序算法，模拟器软件显 示按排序算法对数字进行排序过程中所有轮次的排序结 果。排序算法模拟器软件的用例分析如表1所示。

表1 排序算法模拟器软件用例分析。

\begin{tabular}{|c|c|}
\hline 栏目名称 & 描述 \\
\hline 用例名称 & 排序算法模拟器软件用例分析 \\
\hline 用例标识号 & 001 \\
\hline 参与者 & 学习计算机基础课程的学生 \\
\hline 简要说明 & $\begin{array}{l}\text { 学生用来操作软件, 选择冒泡排序算法或快速排序算法, 排序过程中的中间结果和最后排序结果一步一步显示出来。 } \\
\text { 1. 输入参与排序的一组数字。 }\end{array}$ \\
\hline \multirow{5}{*}{ 基本事件流 } & 2. 选择“冒泡排序算法”或“快速排序算法”。 \\
\hline & 3. 点击“开始”按钮。 \\
\hline & 4. 模拟器软件出现一个文本框, 显示着当前参与排序的数字, 以用户输入的原始顺序排列。 \\
\hline & 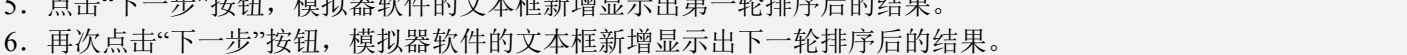 \\
\hline & $\begin{array}{l}\text { 7. 所有轮次排序结束, 点击“下一步”按钮, 模拟器软件的文本框显示出所有轮次的排序结果。 } \\
\text { 8. 用例终止。 }\end{array}$ \\
\hline 其他事件流 & 在点击“开始”按钮之前, 用户随时可以修改参与排序的一组数字。 \\
\hline 异党事件流 & 1. 提示错误信息, 用户确认。 \\
\hline 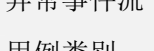 & 2. 返回到模拟器软件主页面。 \\
\hline 用例 & 模块用例 \\
\hline
\end{tabular}

\subsection{2. 模拟器软件实现效果}

在排序算法模拟器软件上运行冒泡排序算法和快速排序算法, 实现效果如图1所示。

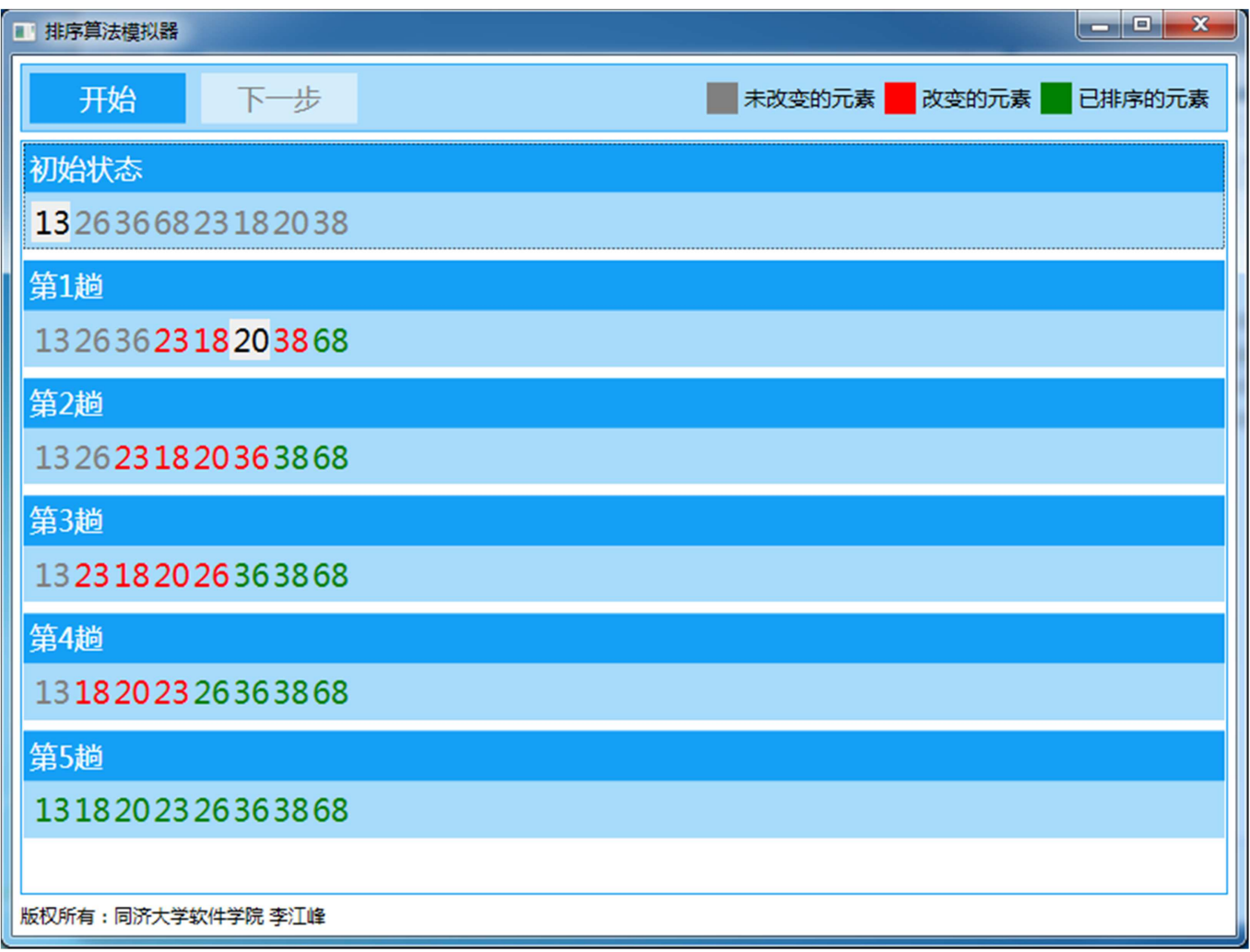

(a)冒泡排序算法实现效果图 


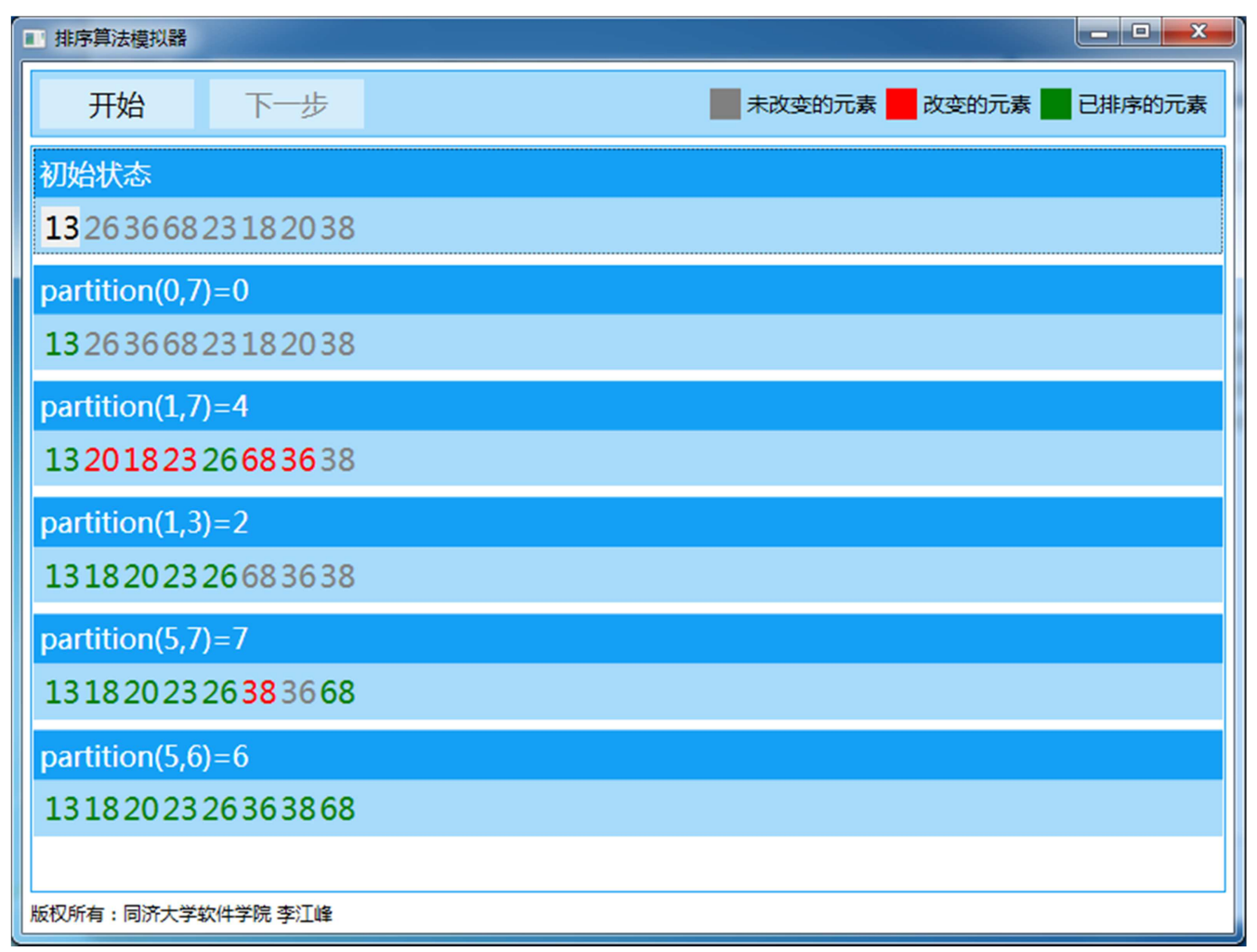

(b)快速排序算法实现效果图

图1 排序算法模拟器软件实现效果图。

\section{2. 二进制运算模拟器软件}

\subsection{1. 模拟仿真实验需求}

在二进制模拟器软件上, 主要运行布尔运算、基于布 尔运算的门操作、二目运算流程三个模拟仿真实验。

模拟器软件的主要需求是:
1) 学生输入参与布尔运算或门操作的元素, 选择布 尔运算或门操作的类型, 模拟器软件运算结果;

2) 学生点击二目运算曹作, 模拟器软件逐步显示二 目运算在机器中的运行流程。

模拟器软件中布尔运算和门操作子模块的用例分析 如表2所示, 二目运算流程子模块的用例分析如表 3 所示。

表2 布尔运算和门操作子模块用例分析。

\begin{tabular}{ll}
\hline 栏目名称 & 描述 \\
\hline 用例名称 & 布尔运算和门操作软件子模块用例分析 \\
用例标识号 & 002 \\
参与者 & 学习计算机基础课程的学生 \\
简要说明 & 学生用来操作软件, 选择某种类型的布尔运算和参与运算的元素, 显示布尔运算或门操作的运算结果。 \\
& 1. 选择参与布尔运算的元素 (0或 1 。 \\
& 2. 选择布尔运算类型 (与、或、异或)。 \\
& 3. 软件界面显示布尔运算结果。 \\
& 4. 选择参与门操作的元素 $(0$ 或 1$)$ 。 \\
基本事件流 & 5. 选择门操作类型 (与、或、异或)。 \\
& 6. 软件界面显示门操作的运算结果。 \\
& 7. 用例终止。 \\
其他事件流 & 无 \\
异常事件流 & 1. 提示错误信息, 用户确认。 \\
用例类别 & 2. 返回到模拟器软件主页面。 \\
\hline
\end{tabular}

表3 二目运算流程软件子模块用例分析。

\begin{tabular}{ll}
\hline 栏目名称 & 描述 \\
\hline 用例名称 & 二目运算流程软件子模块用例分析 \\
用例标识号 & 003 \\
参与者 & 学习计算机基础课程的学生 \\
简要说明 & 学生用来操作软件, 显示二目运算在计算机硬件中的的运行流程。 \\
基本事件流 & 1 .点击“开始”按钮, 二目运算操作开始运行。 \\
\hline
\end{tabular}




\begin{tabular}{ll}
\hline 栏目名称 & 描述 \\
\hline & 2. 点击“下一步”按钮, 显示参与运算的第一步流程。 \\
& 3. 再次点击“下一步”钮, 显示参与运算的第二步的流程, 直到二目运算运行完毕。 \\
& 4. 依次点击“下一步”按钮, 显示参与运算的每一步的流程。 \\
& 5. 二目运算运行完毕。 \\
& 6. 用例终止。 \\
其他事件流 & 无。 \\
异常事件流 & 1. 提示错误信息, 用户确认。 \\
用例类别 & 2. 返回到模拟器软件主页面。 \\
\hline
\end{tabular}

\subsection{2. 模拟器软件实现效果}

在二进制运算模拟器软件上运行布尔运算和门操作, 以及二目运算流程实现, 实现效果如图2所示。

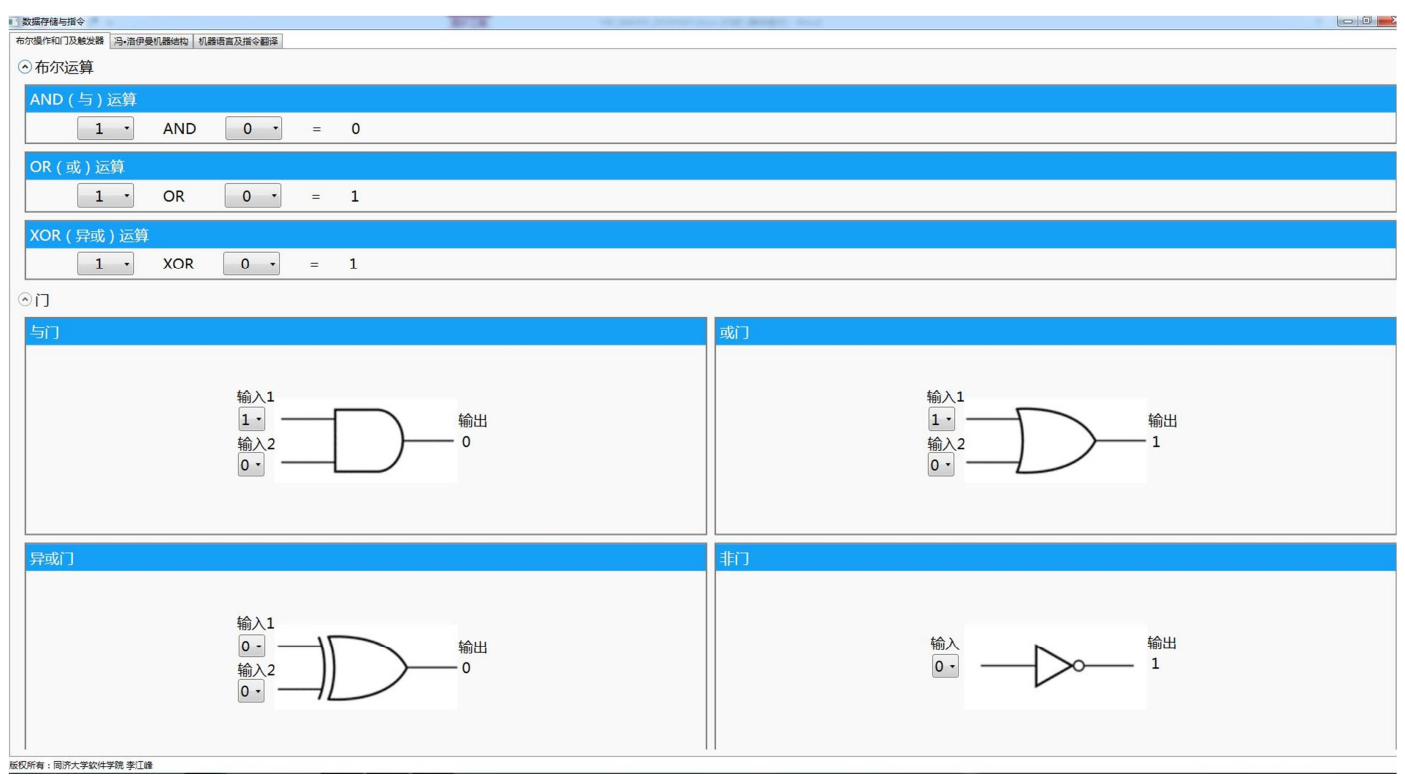

(a)布尔运算和门操作实现效果图

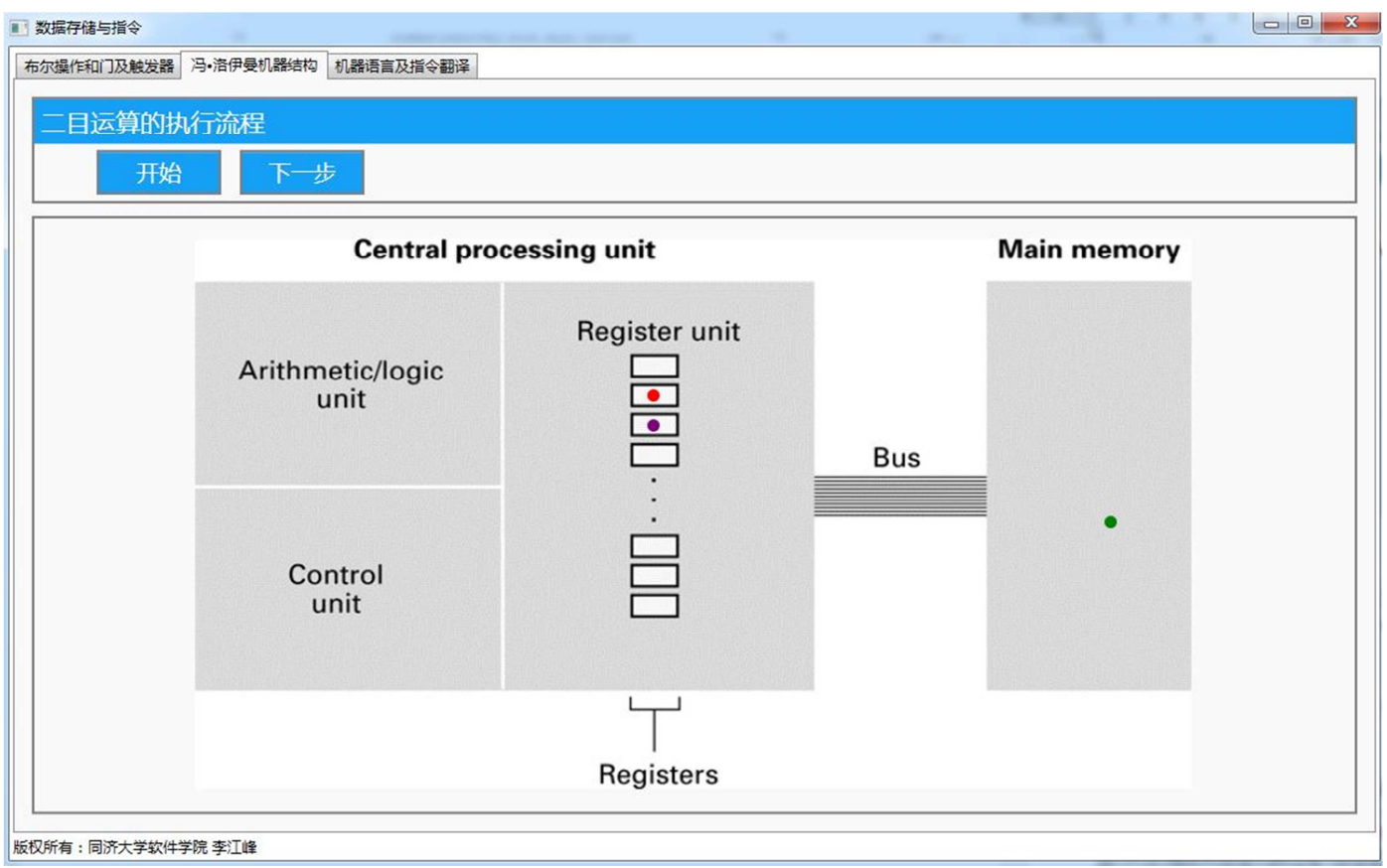

(b)二目运算流程实现效果图

图2 二进制运算模拟器软件实现效果图。 


\section{3. 进程管理模拟器软件}

\subsection{1. 模拟仿真实验需求}

在进程管理模拟器软件上, 主要运行进程状态分析 和多进程运行演示两个模拟仿真实验。模拟器软件的主 要需求是: 分析进程的状态及其转换规律、演示多进程 运行时的调度和进程切换过程。进程管理模拟器软件的
用例分析如表 4 所示。

\subsection{2. 模拟器软件实现效果}

进程管理模拟器软件上运行进程状态、多进程运行演 示两个实验, 实现效果如图3所示。

表4 进程管理模拟器软件用例分析。

\begin{tabular}{ll}
\hline 栏目名称 & 描述 \\
\hline 用例名称 & 进程管理模拟器软件用例分析 \\
用例标识号 & 004 \\
参与者 & 学习计算机基础课程的学生 \\
简要说明 & 学生用来操作软件, 选择进程状态、多进程运行演示, 软件界面显示进程的状态及其转换规律、多进程运行的进程运行过程。 \\
& 1. 选择“进程状态”栏目, 显示进程运行、就绪、阻塞三种状态, 以及种进程状态间的转换方向。 \\
& 2. 选择“多进程运行演示”栏目, 以三个进程同时工作为例, 显示多进程工作时的时间片轮流调度过程, 包括进程的调度及进程 \\
基本事件流 & $\begin{array}{l}\text { 的切换过程。 } \\
\end{array}$ \\
3. 用例终止。 \\
其他事件流 & 用户随时可以选择“进程状态”、“多进程运行演示”的任一栏目, 这三个栏目的运行不分先后顺序。 \\
异常事件流 & 1. 提示错误信息, 用户确认。 \\
用例类别 & 2. 返回到模拟器软件主页面。 \\
\hline
\end{tabular}

\section{4. 结论}

本文首先介绍了模拟仿真技术应用在课程教学中的 意义, 以及现有应用方法。接着, 分析了计算机基础课程 的特点, 包括课程内容的的基础性、入门学习的复杂性、 兴趣培养的必要性。然后, 设计并实现了计算机基础课程 中的仿真模拟器软件及其相关模拟仿真实验。

设计并实现的仿真模拟器软件包括排序算法模拟器 软件、二进制运算模拟器软件、进程管理模拟器软件。在
这三个模拟器软件之上, 分别运行冒泡排序算法、快速排 序算法、布尔运算和门操作、二目运算流程、进程状态、 多进程运行演示共6个模拟仿真实验。

这些仿真模拟器软件和模拟仿真实验已经用于 2016 年-2018年计算机基础课堂上的教学, 教学效果很好。

未来, 在已有模拟器软件的基础上, 更多的模拟器软 件及其相关模拟仿真实验将被设计并开发, 用于计算机专 业课程的课堂教学中。

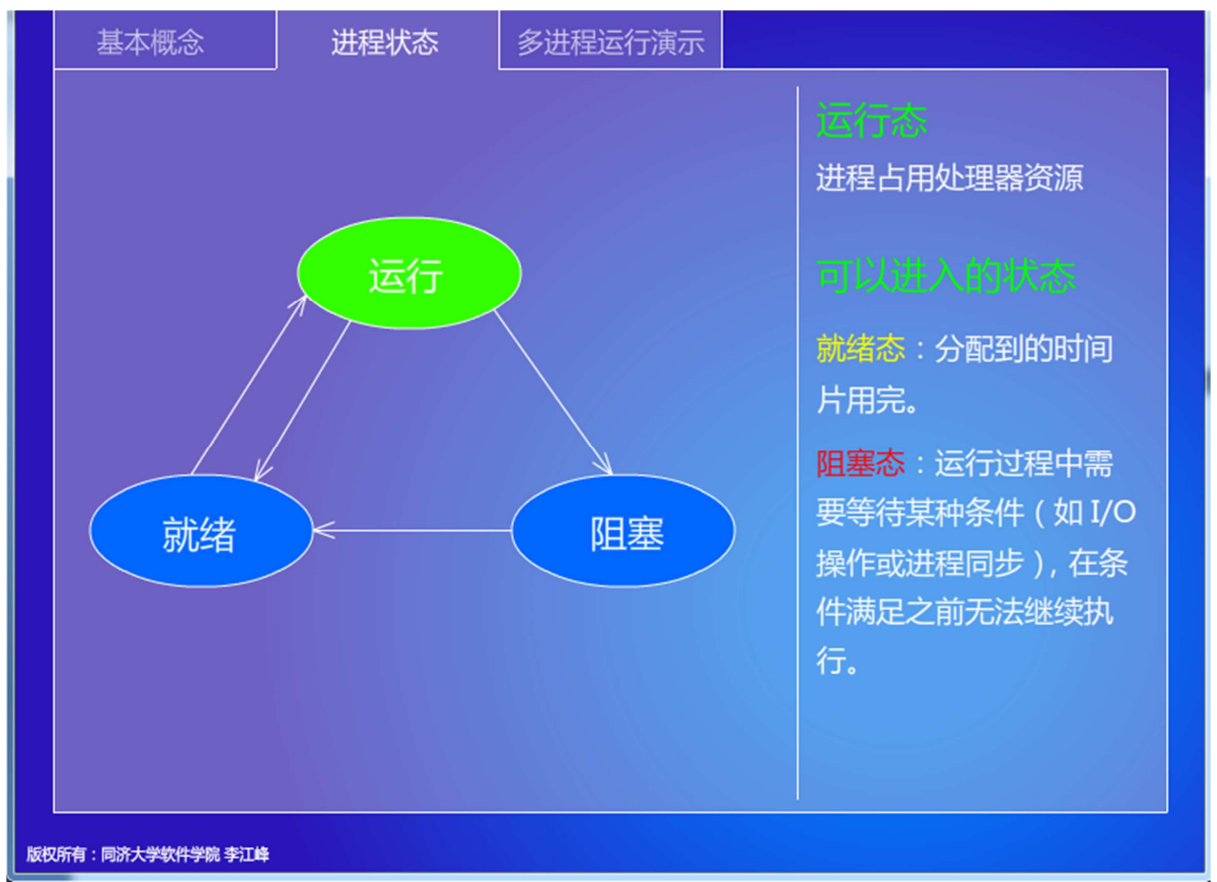

(a)进程状态实现效果图 


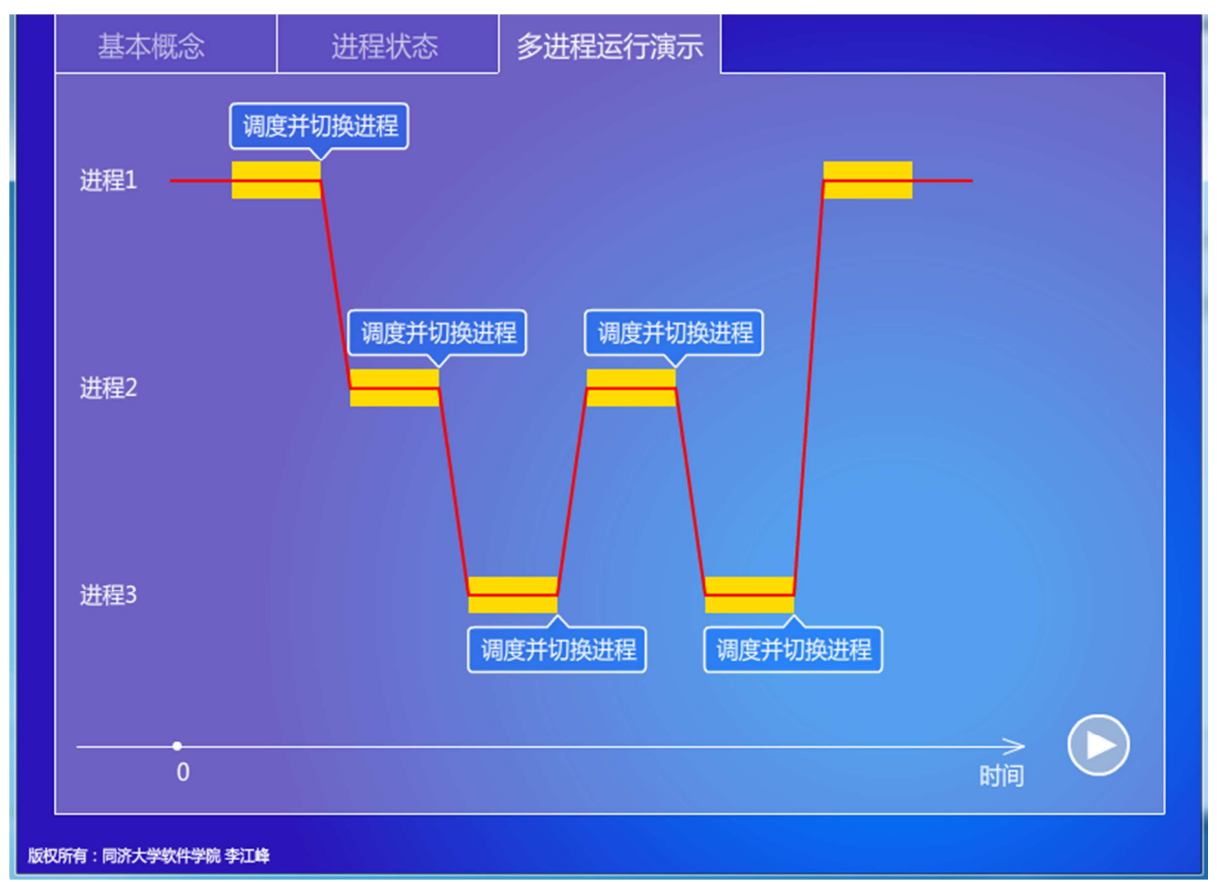

(b)多进程运行演示实现效果图

图3 进程管理模拟器软件实现效果图。

\section{参考文献}

[1] 王俊洁.基于 $3 \mathrm{D}$ 模拟仿真平台的高校实训教学环境构建技 术研究[J/OL].现代电子技术, 2018(19):183-186[2018-10-02]. https://doi.org/10.16652/j.issn.1004-373x.2018.19.043。

[2] 周凤玲,魏中盖. 电脑模拟仿真技术在电子维修教学中的运 用探析[J].中国新通信,2017,19(22):129。

[3] 何伟.互联网+背景下高职《电子商务》课程实践教学改革 [J].电子商务,2017(10):74-76。

[4] 任国成, 赵忠魁, 徐淑波, 刘科高. 数值模拟在材料成形原理中 的教学应用研究—以山东建筑大学为例 [J]. 山东建筑大 学学报,2017,32(01):98-102。

[5] 林威. 模拟仿真教学法在英语专业实训课程中的应用与研 究[J].现代经济信息,2016(16):425。
[6] 陈智,王莹. 基于模拟仿真技术的物流管理实践教学方法研 究[J].物流工程与管理,2016,38(07):291-292+257。

[7] 彭振宇.网络环境下的计算机基础课程分类分层次教学与 实践 $[J]$.信息与电脑(理论版),2018(17):240-241。

[8] 刘锋,郭维威,赵晓敏,李晓艳.基于“互联网+”教学模式的大 学计算机基础课程改革研究[J]. 黑龙江工业学院学报(综合 版),2018,18(09):30-32。

[9] 万振环. 以岗位胜任力为导向的大学计算机基础课程教学 研究[J].计算机时代,2018(09):82-84。

[10] 丽丽.计算思维在计算机科学导论课程改革中的作用 $[\mathrm{J}]$.电 子商务,2018(06)。

[11] 邹羚.大学计算机基础教学改革的探索 [J].教育教学论 坛,2017(45)。

[12] 王茹娟. 高等教育中计算思维问题的探索 [J]. 高教学 刊.2017(04)。 